\title{
DEFINICIÓN DE COMPENTENCIAS PROFESIONALES PEDAGÓGICAS EN LA FORMACIÓN DOCENTE EN GEOGRAFÍA
}

\author{
Pedro Álvarez Cruz ${ }^{1}$ \\ pealcruz@gmail.com \\ UNIVERSIDAD DE CIENCIAS PEDAGÓGICAS \\ "ENRIQUE JOSÉ VARONA" \\ LA HABANA - CUBA
}

Recibido: 27 de abril de 2017

Aceptado: 28 de abril de 2018

DOI: http://dx.doi.org/10.15366/didacticas2018.19.002

\section{Resumen}

El presente artículo tiene como objetivo exponer la definición de las competencias profesionales pedagógicas, generales y específicas, en las que se debe basar la formación docente en Geografía. Este estudio se utilizó una metodología de investigación documental; apoyada en diversas técnicas, tales como: lectura de fuentes documentales, recopilación de datos y presentación de la información. El artículo muestra las competencias profesionales pedagógicas generales y específicas a tener en cuenta en la formación docente en Geografía.

Palabras clave: Formación docente; competencia profesional pedagógica; capacidad profesional pedagógica; habilidad profesional pedagógica.

\begin{abstract}
The present article has as objective to expose the definition of the pedagogic professional competences, general and specific, in those that the educational formation should be based on Geography. This study was used a methodology of documental investigation; supported in diverse technical, such as: reading of documental sources, summary of data and presentation of the information. The article shows the pedagogic professional competences, general and specific, to keep in mind in the educational formation in Geography.
\end{abstract}

Keywords: Educational formation; pedagogic professional competence; pedagogic professional capacity; pedagogic professional ability.

\footnotetext{
${ }^{1}$ Licenciado en Educación en la Especialidad de Geografía (2004). Máster en Didáctica de las Ciencias Naturales (2008). Doctor en Ciencias Pedagógicas (2014). Profesor Titular. Universidad de Ciencias Pedagógicas “Enrique José Varona”, La Habana, Cuba.
} 


\section{1.- INTRODUCCIÓN}

La educación superior, en Cuba, inició el año lectivo, 2016-2017, con una nueva generación de planes de estudio (Plan E) en los cursos de formación docente. Esta transformación se realizó como parte del perfeccionamiento continuo, que ha caracterizado a todo el Sistema Nacional de Educación en los últimos cincuenta y ocho años. La principal modificación, de este nuevo plan, se expresa en la formación docente en una especialidad, es decir, los cursos de licenciatura en educación existentes, de doble especialidad, tales como: Matemática-Física, Biología-Química, Biología-Geografía y Educación Laboral-Informática; se modificaron en un solo perfil disciplinar, restituyéndose así la formación docente en especialidades independientes y, en particular, la formación docente en Geografía.

La formación docente en Geografía en este nuevo plan de estudio, orientado a la solución de problemas generales y frecuentes de la profesión, pretende responder a las exigencias de una formación continua portadora de conocimientos, habilidades, hábitos y actitudes esenciales; que propicien el desarrollo de capacidades pedagógicas manifiestas en un desempeño competente en el cumplimiento de las funciones profesionales pedagógicas en el eslabón de base de la profesión, es decir, el centro laboral: la escuela.

Este docente de Geografía, destinado a laborar en escuelas secundarias básicas e institutos preuniversitarios, también debe manifestar competencias profesionales para el enfrentamiento a los desafíos actuales de la educación geográfica; la que es definida como un proceso de trasmisión y apropiación de conocimientos, habilidades, hábitos y actitudes vinculadas a la ciencia geográfica en el contexto escolar o no, es decir, formal escolarizado- e informal -no escolarizado-; lo que significa enseñar y aprender a comprender las complejas relaciones naturaleza-naturaleza, sociedad-naturaleza y sociedad-sociedad, en un lugar concreto del espacio geográfico y determinado, escalarmente, a nivel local, regional o global.

Por tanto, la formación docente en Geografía no solo tiene el reto de concebirse contextualizada con las necesidades económicas y las características socioculturales de la nación sino que, además debe hacerlo en su contribución a la solución de problemas y necesidades a escala local, nacional, regional y mundial.

A pesar de la importancia de una formación integral de dicho profesional, aún debe trabajarse en la definición de las competencias profesionales, que le deben caracterizar en su labor y en el enfrentamiento de los retos expuestos. El estudio que se presenta tiene por objetivo exponer la definición de las competencias profesionales, generales y específicas, en las que se debe basar la formación docente en Geografía. 


\section{2.- MÉTODOS Y MATERIALES}

Este estudio se realizó mediante una investigación documental, en la que se procedió a la recogida, comparación, análisis, síntesis, abstracción y generalización de la información sobre la formación docente basada en competencias profesionales. Esto se realizó a partir de la utilización de las diversas técnicas de la investigación documental: lectura de fuentes documentales, recopilación de datos y presentación de la información.

\section{3.- RESULTADOS Y DISCUSIÓN}

\section{1.- Situación real de los estudios de la formación docente basados en competencias profesionales}

La formación profesional en la educación superior basada en competencias, en Cuba, se encuentra en un momento de reflexión teórica con discretos avances en la práctica. La reserva se debe, probablemente, a la disquisición teórica existente entre la definición constitutiva y operacional del concepto «competencia» y otros constructos análogos en su esencia, tales como: «habilidad», «hábito», «capacidad» y «aptitud».

Esta reserva también puede deberse a la marcada influencia en la teoría pedagógica, en las décadas de los años 1970 a 1990, de las teorías pedagógicas procedentes de los países de Europa del Este y de la Unión de Repúblicas Socialistas Soviéticas. Contrastan, en este sentido, varios estudios sobre la formación de las capacidades, tales como: Venguer (1975), Leites, Leontiev, Rubinstein \& Tieplov In. Iliasov \& Yaliaodis (1986); cuyas ideas sobre una «pedagogía de las capacidades» pueden hacer interpretar la «competencia» como un constructo añadido por la modernidad y la influencia ineludible, en el contexto educacional, de los modelos de competencia del mercado que se manifestaron con fuerza desde finales del siglo XIX y principios del XX en el ámbito educativo. García, et al. (2011) opinan en relación con el enfoque de la formación profesional en Cuba, que:

«...se ha guiado hacia la formación de habilidades práctico-profesionales, en un inicio solo para los años terminales, posteriormente para todos los años, pero sin el vínculo necesario entre la Universidad y la práctica social. Con la incorporación de los Planes C y posteriormente $\mathrm{C}$ perfeccionado se ha venido ganando en cuanto a la vinculación con los sectores productivos y de servicios pero persisten aun en los Planes D dificultades en cuanto a su vínculo directo desde la universidad y para la empresa.» (p. 71)

No obstante, el interés de muchos pedagogos cubanos por una formación profesional basada en competencias comenzó a hacerse creciente a finales del siglo XX y a principios del XXI.

Este interés se ha manifestado con pujanza en diferentes investigaciones educativas, entre las que interesa destacar aquellas relacionadas con la formación docente, tales como: Fernández (1996), que investigó sobre la competencia comunicativa como factor de 
eficiencia profesional del educador; Parra (2002), que propuso un modelo para la dirección del desarrollo de la competencia profesional didáctica en la formación docente inicial; Pino (2003), que presentó un modelo para el aprendizaje de las habilidades profesionales como base para la formación de competencias profesionales; Nieto (2005), que contribuyó al perfeccionamiento de las competencias profesionales en la actividad educativa de los profesores de los institutos superiores pedagógicos; Martínez (2007), que investigó sobre las competencias tutoriales de los docentes de la educación media en la formación del profesor general integral en el contexto de la universalización pedagógica; Páez (2007), que trató el tema de las competencias en la formación del profesional de la educación desde una perspectiva martiana y marxista; y Cardoso (2008), que propuso un modelo del desempeño por competencias profesionales del director de escuela primaria. Actualmente, son muchas las investigaciones científicas en el contexto nacional y de la formación docente, que prueban la pertinencia pedagógica del tema y sirven de referentes inmediatos en cualquier estudio relacionado con la temática de las competencias profesionales.

La formación docente, basada en competencias profesionales, constituye un problema que demanda soluciones integrales y contextualizadas con las necesidades reales de cada lugar; los que demandan, dada la complejidad del mundo actual, una formación docente permanente y de calidad.

La formación docente, en Cuba, se sustenta en un modelo de formación continua que inicia en la formación de pregrado, en el que se educa al individuo para su labor en el eslabón de base. Esta formación inicial se complementa, luego egresado, con la preparación para el empleo y las diferentes formas de formación posgraduada, es decir, la superación profesional -curso, entrenamiento y diplomado- y la formación académica -especialidad, maestría y doctorado-.

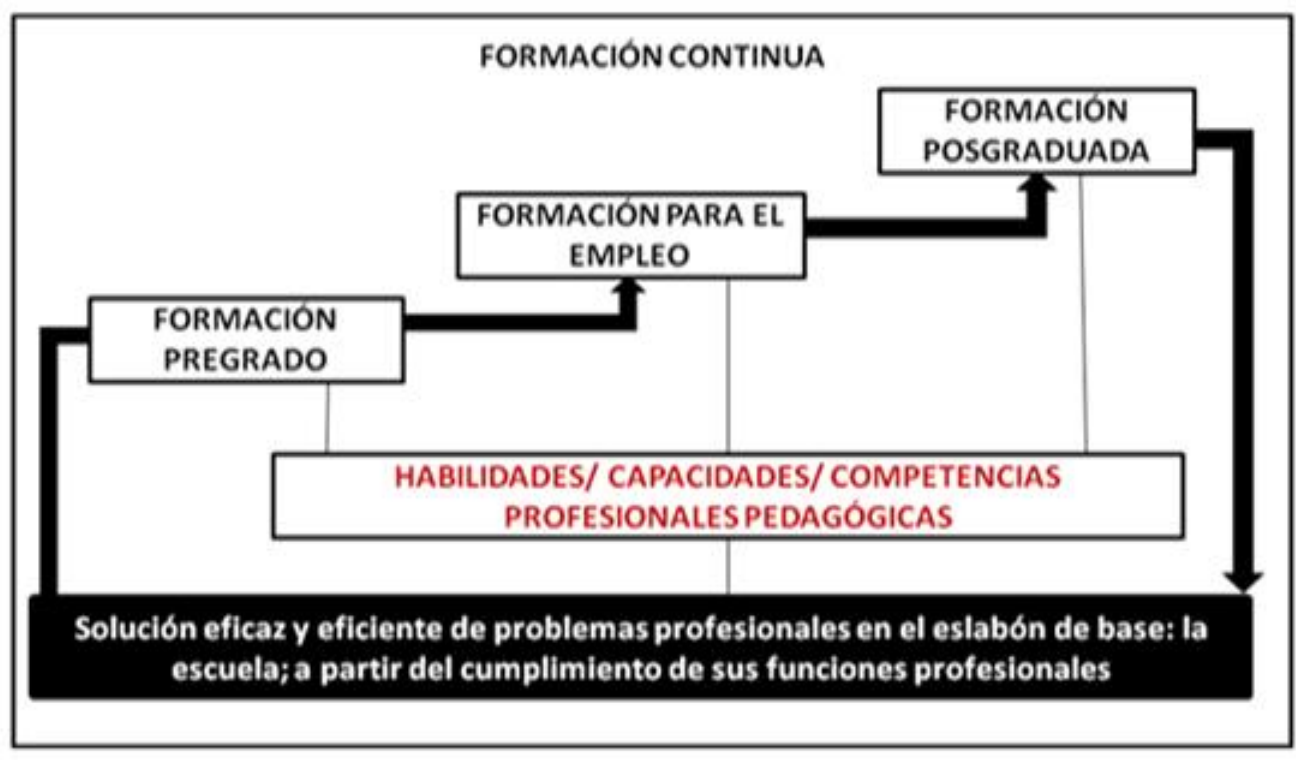

Gráfica 1. Modelo de formación docente en Cuba 
Este sistema de formación continua se centra en el desarrollo de habilidades, capacidades y competencias profesionales pedagógicas, que deberá poseer este profesional para la solución eficaz y eficiente de problemas en el eslabón de base; a partir del cumplimiento de sus funciones profesionales:

- Función docente-metodológica: relacionada con el desarrollo de la actividad profesional fundamental, que es la dirección del proceso de enseñanzaaprendizaje de la ciencia escolar que se enseña.

- Función orientación educativa: relacionada con la actividad profesional, que permite una formación integral de la personalidad; a partir del diagnóstico de las necesidades educativas $y$, en particular, del aprendizaje; para su corrección mediante acciones preventivas y de intervención individual, grupal, familiar y comunitario.

- Función investigación-superación: relacionada con la actividad profesional de solución de problemas profesionales, presentes en el eslabón de base, mediante la utilización de métodos de la investigación educacional que adquiere y optimiza en su auto-superación y superación profesional.

Estas funciones profesionales pedagógicas, contextualizadas en cada carrera pedagógica, son utilizadas como sustento en la definición de las habilidades, capacidades y competencias profesionales de carácter pedagógico. También se tienen en cuenta en esta determinación: el objeto de la profesión, el campo de acción, los problemas profesionales y los objetivos generales determinados en el modelo del profesional (MES, Cuba, 2016).

\section{2.- Competencia profesional pedagógica: su conceptuación en el contexto de la formación docente}

La definición de las competencias profesionales, de carácter pedagógico, constituyen en el actual modelo de formación docente una tarea pendiente que debe resolverse, esencialmente, a partir de la valorización de las relaciones existentes entre la habilidad profesional, la capacidad profesional y la competencia profesional; considerándose esta última como un constructo relacionado con los anteriores.

La habilidad profesional pedagógica es un sistema de procedimientos de carácter pedagógico, característicos en cada habilidad, que se configuran en las estructuras psíquicas y se manifiestan en la actividad profesional del docente, es decir, en su capacidad para realizar competentemente la labor educativa $\mathrm{y}$, particularmente, la dirección del proceso de enseñanza y de aprendizaje.

La capacidad profesional pedagógica o capacidad pedagógica, según el psicopedagogo ruso Petrovsky (s/f), es «...una determinada combinación de características psíquicas de la personalidad, que son la condición para el logro de altos 
resultados en el proceso de enseñanza y educación...» (p.394). El propio Petrovsky (s/f) consideró que el desarrollo de las capacidades profesionales pedagógicas está estrechamente vinculado al dominio de habilidades profesionales pedagógicas, cuya ejercitación influye en la formación y el desarrollo de las capacidades profesionales pedagógicas. La capacidad profesional pedagógica es parte de la actividad profesional pedagógica del docente y también su resultado; que se manifiesta, forma y desarrolla en la estructura general de las propiedades psíquicas y se expresa en su actividad profesional.

Actualmente, la formación basada en capacidades se sustenta desde la «teoría del desarrollo humano» propuesta por el economista indio Amartya Kumar Sen (1933- ), quien consideró, en el desarrollo de los indicadores económicos y sociales, la significación de las «capacidades» de cada persona para poder revertir una situación negativa. Esta posición ha trascendido a la educación a partir de las aportaciones realizadas por Nussbaum (2001), Walker (2006) y otros.

Tejeda \& Sánchez (2008) y Achiong \& Deniz (2012) definen la competencia profesional, revelando sus relaciones existentes con la capacidad profesional e, incluso, con la habilidad profesional:

- «...una cualidad humana que se configura como síntesis dialéctica en la integración funcional del saber (conocimientos diversos), saber hacer (habilidades, hábitos, destrezas y capacidades) y saber ser (valores y actitudes), que son movilizados en un desempeño idóneo a partir de los recursos personológicos del sujeto, que le permiten saber estar en un ambiente socioprofesional y humano en correspondencia con las características y exigencias complejas del entorno». (Tejeda \& Sánchez, 2008, p.21)

- «...la configuración psicológica que integra componentes cognitivos, metacognitivos, procedimentales, motivacionales y actitudinales, y que se expresa en un conjunto estructurado y dinámico de conocimientos, habilidades, actitudes, valores y cualidades, resultantes de un proceso de formación, que permiten al individuo solucionar mediante un desempeño eficiente en ciertas condiciones de trabajo y cultura organizacional, los problemas inherentes al objeto de su profesión, en correspondencia con las funciones, tareas y cualidades que respondan a las demandas del desarrollo social en un contexto histórico concreto». (Achiong \& Deniz, 2012, p.6)

Muestran estos autores la articulación entre los conocimientos, las habilidades y las capacidades, los cuales se configuraran mediante la actividad consciente durante el proceso formativo y el desempeño profesional; y son expresados de forma integrada y contextualizada en dicho desempeño. Esto permite interpretar a la competencia profesional como una síntesis en la que se integran aspectos cognitivo-instrumentales y afectivo-volitivos, para explicar el funcionamiento exitoso de la personalidad en un contexto dado y manifiesto en un desempeño eficaz y eficiente. 
Lo antes expuesto, permite definir la competencia profesional pedagógica como un constructo socio-psicológico que manifiesta integralmente el desarrollo de las áreas cognitivo-instrumental y afectivo-volitiva de un individuo, a partir de sus aptitudes, conocimientos, habilidades, hábitos y capacidades en la realización eficaz y eficiente de la actividad docente; en la que demuestra su idoneidad para el desempeño de sus funciones profesionales pedagógicas en la educación e instrucción de las diferentes generaciones.

En síntesis, puede concluirse, desde los puntos de vista antes analizados, que la distinción entre la habilidad profesional, la capacidad profesional y la competencia profesional se expresan en la actividad profesional del individuo y en los resultados que este obtiene.

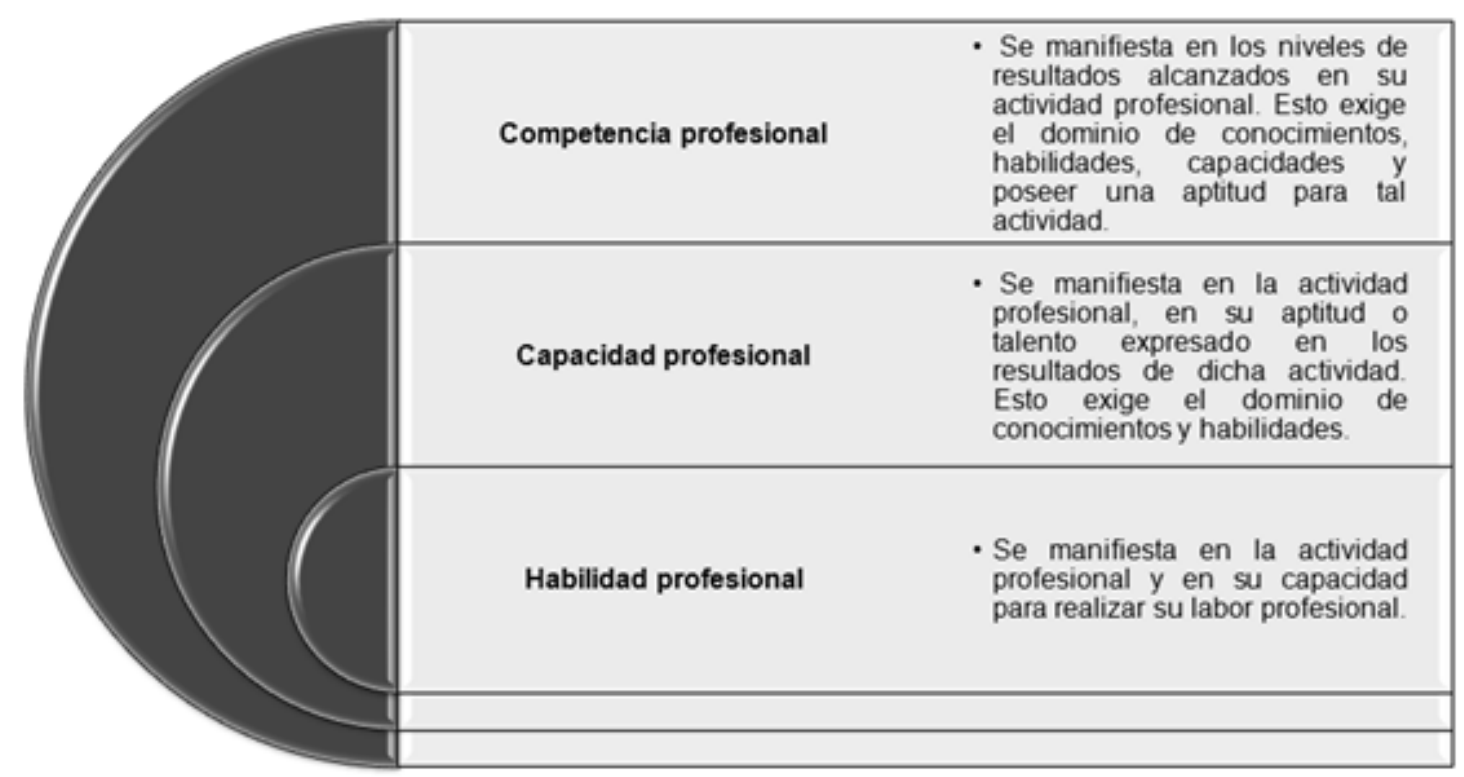

Gráfica 2. Relaciones existentes entre habilidad, capacidad y competencia

«Las competencias surgen en el mundo del trabajo, en la esfera económicoproductiva y, poco a poco, van reduciendo el espacio entre el ámbito educativo y el laboral, vinculándose directamente a la formación y habilidades adquiridas con el empleo.» (García, et al., 2011, p.71). La habilidad profesional, la capacidad profesional y la competencia profesional se construyen e integran en las estructuras psíquicas y se proyectan en la actividad laboral del individuo; valorándose bajo criterios -indicadorespreestablecidos como hábil, capaz, apto o competente para su función profesional.

\section{3.- Una formación docente en Geografía basada en competencias profesionales}

La formación docente basada en competencias profesionales es, más que tema del momento, una línea de investigación necesaria en el contexto socioeducativo complejo 
que se muestra en la actualidad. Por un lado, los acelerados avances tecnológicos que demandan la constante actualización de los ciudadanos para su uso eficaz y eficiente en la solución de sus problemas; y por otro, una sociedad metamorfoseada por su propia evolución y por los riesgos crecientes de un hábitat devastado. Esto exige a la educación $\mathrm{y}$, en particular, a su actor dirigente principal -el docente-, el dominio de competencias para enseñar a dicha sociedad a resolver eficaz y eficientemente sus problemas.

En este empeño de una formación docente, basada en competencias profesionales, se examinaron trabajos muy valiosos; cuyas propuestas contribuyeron a definir las competencias profesionales de un docente de Geografía en la actualidad; entre los que vale destacar al «Proyecto de Definición y Selección de Competencias -DeSeCo-» (OCDE, 1997), al «Proyecto Tuning América Latina» (Beneitone et al., 2007) y el libro «Diez nuevas competencias para enseñar» (Perrenoud, 2004).

En el informe del Proyecto DeSeCo el concepto competencia es considerado más que conocimientos y habilidades; aunque incluye la habilidad de enfrentar demandas complejas, apoyándose en y movilizando recursos psicosociales (incluyendo habilidades $\mathrm{y}$ actitudes) en un contexto en particular. Desde ese punto de vista se exponen competencias clave en tres amplias categorías. Primero, los individuos deben poder utilizar un amplio rango de herramientas para interactuar efectivamente con el ambiente físico y virtual, como en la tecnología de la información y socioculturales, como en el uso del lenguaje. Necesitan comprender dichas herramientas ampliamente, como para adaptarlas a sus propios fines, utilizar las herramientas de manera interactiva. Segundo, en un mundo cada vez más interdependiente, los individuos necesitan poder comunicarse con otros, y debido a que encontrarán personas de diversos orígenes, es importante que puedan interactuar en grupos heterogéneos. Tercero, los individuos necesitan poder tomar la responsabilidad de manejar sus propias vidas, situar sus vidas en un contexto social más amplio y actuar de manera autónoma.

El informe del «Proyecto Tuning América Latina» considera la competencia como una combinación dinámica de atributos, en relación con procedimientos, habilidades, actitudes y responsabilidades, que describen los encargados del aprendizaje de un programa educativo o lo que los alumnos son capaces de demostrar al final de un proceso educativo. En dicho informe se elaboró una lista de competencias genéricas y específicas para diferentes áreas de formación, entre ellas la formación docente:

1. Domina la teoría y la metodología curriculares para orientar acciones educativas (diseño, ejecución y evaluación).

2. Domina los saberes de las disciplinas del área de conocimiento de su especialidad.

3. Diseña y opera estrategias de enseñanza y aprendizaje según contextos.

4. Proyecta y desarrolla acciones educativas de carácter interdisciplinario. 
5. Conoce y aplica en el accionar educativo las teorías que fundamentan la didáctica general y específica.

6. Identifica y gestiona apoyos para atender necesidades educativas determinadas en diferentes contextos.

7. Diseña e implementa diversas estrategias y procesos de evaluación de aprendizajes con base en criterios determinados.

8. Diseña, gestiona, implementa y evalúa programas y proyectos educativos.

9. Selecciona, elabora y utiliza materiales didácticos pertinentes al contexto.

10. Crea y evalúa ambientes favorables y desafiantes para el aprendizaje.

11. Desarrolla el pensamiento lógico, crítico y creativo de los educandos.

12. Logra resultados de aprendizaje en diferentes saberes y niveles.

13. Diseña e implementa acciones educativas que integran a personas con necesidades educativas especiales.

14. Selecciona, utiliza y evalúa las tecnologías de la comunicación e información como recurso de enseñanza y aprendizaje.

15. Educa en valores, en formación ciudadana y en democracia.

16. Investiga en educación y aplica los resultados en la transformación sistemática de las prácticas educativas.

17. Genera innovaciones en distintos ámbitos del sistema educativo.

18. Conoce la teoría educativa y hace uso crítico de ella en diferentes contextos.

19. Reflexiona sobre su práctica para mejorar su quehacer educativo.

20. Orienta y facilita, con acciones educativas, los procesos de cambio en la comunidad.

21. Analiza críticamente las políticas educativas.

22. Genera e implementa estrategias educativas que respondan a la diversidad sociocultural.

23. Asume y gestiona, con responsabilidad, su desarrollo personal y profesional en forma permanente.

24. Conoce los procesos históricos de la educación de su país y Latinoamérica.

25. Conoce y utiliza las diferentes teorías de otras ciencias que fundamentan la educación: Linguística, filosofía, sociología, psicología, antropología, política e historia.

26. Interactúa social y educativamente con diferentes actores de la comunidad para favorecer los procesos de desarrollo.

27. Produce materiales educativos acordes con diferentes contextos para favorecer los procesos de enseñanza y aprendizaje. 
El libro «Diez nuevas competencias para enseñar» (2004), escrito por el destacado sociólogo suizo Philippe Perrenoud, que considera a la competencia como una capacidad de movilizar varios recursos cognitivos para hacer frente a un tipo de situaciones. Perrenoud (2004) considera cuatro aspectos clave en la comprensión de la competencia:

1. «Las competencias no son en sí mismas conocimientos, habilidades o actitudes, aunque movilizan, integran, guían tales recursos.

2. Esta movilización solo resulta pertinente en situación, y cada situación es única, aunque se le puede tratar por analogía con otras, ya conocidas.

3. El ejercicio de la competencia pasa por operaciones mentales complejas, sostenidas por esquemas de pensamiento, los cuales permiten determinar (más o menos de un modo consciente y rápido) y realizar (más o menos de un modo eficaz) una acción relativamente adaptada a la situación.

4. Las competencias profesionales se desarrollan en formación, pero también a merced de la experiencia cotidiana del practicante, de una situación de trabajo a otra». (p.11)

Las competencias profesionales definidas en su obra son organizadas en diez grupos:

1. Organizar y animar situaciones de aprendizaje.

2. Gestionar la progresión de los aprendizajes.

3. Elaborar y hacer evolucionar dispositivos de diferenciación.

4. Implicar a los alumnos en sus aprendizajes y en su trabajo.

5. Trabajar en equipo.

6. Participar en la gestión de la escuela.

7. Informar e implicar a los padres.

8. Utilizar las nuevas tecnologías.

9. Afrontar los deberes y los dilemas éticos de la profesión.

10. Organizar la propia formación continua.

Partiendo de dichos referentes y, fundamentalmente, de los postulados expuestos en el modelo del profesional (MES, Cuba, 2016), tales como: el objeto de la profesión, el campo de acción, los problemas profesionales, los objetivos generales determinados y las funciones profesionales y sus tareas respectivas. Se procedió a nombrar y definir, para su posterior instrumentación empírica, evaluación y generalización, las competencias profesionales pedagógicas siguientes: 


\begin{tabular}{|c|c|c|}
\hline No. & $\begin{array}{l}\text { COMPETENCIA } \\
\text { PROFESIONAL } \\
\text { PEDAGÓGICA GENERAL }\end{array}$ & $\begin{array}{l}\text { COMPETENCIA PROFESIONAL } \\
\text { PEDAGÓGICA ESPECÍFICA }\end{array}$ \\
\hline \multirow[t]{4}{*}{1} & \multirow{4}{*}{$\begin{array}{l}\text { Comprende las complejas } \\
\text { relaciones naturaleza- } \\
\text { naturaleza, naturaleza-sociedad } \\
\text { y sociedad-sociedad, en un lugar } \\
\text { concreto del espacio geográfico } \\
\text { y determinado, escalarmente, a } \\
\text { nivel local, regional o global. }\end{array}$} & $\begin{array}{l}\text { Establece analogías entre fenómenos, procesos y } \\
\text { hechos geográficos a nivel local, regional o } \\
\text { global, mediante el trabajo de campo, cartográfico } \\
\text { y tecnológico. }\end{array}$ \\
\hline & & $\begin{array}{l}\text { Analiza fenómenos, procesos y hechos } \\
\text { geográficos a nivel local, regional o global, } \\
\text { mediante el trabajo de campo, cartográfico y } \\
\text { tecnológico. }\end{array}$ \\
\hline & & $\begin{array}{l}\text { Construye representaciones de fenómenos, } \\
\text { procesos y hechos geográficos a nivel local, } \\
\text { regional o global, mediante el trabajo de campo, } \\
\text { cartográfico y tecnológico. }\end{array}$ \\
\hline & & $\begin{array}{l}\text { Aplica sus saberes geográficos en la solución de } \\
\text { problemas medioambientales y de ordenación } \\
\text { territorial desde su actuación como educador } \\
\text { geográfico, es decir, profesor de Geografía. }\end{array}$ \\
\hline \multirow[t]{3}{*}{2} & \multirow{3}{*}{$\begin{array}{l}\text { Diagnostica las necesidades } \\
\text { instructivas y educativas del } \\
\text { alumno en materia geográfica, } \\
\text { así como los niveles de } \\
\text { influencia -comunidad, escuela, } \\
\text { familia y grupo- en la } \\
\text { satisfacción de dichas } \\
\text { necesidades. }\end{array}$} & $\begin{array}{l}\text { Recoge información en los diferentes niveles de } \\
\text { influencia en la identificación de las necesidades } \\
\text { de aprendizaje en materia geográfica del alumno y } \\
\text { sus causas. }\end{array}$ \\
\hline & & $\begin{array}{l}\text { Caracteriza los diferentes niveles de influencia y, } \\
\text { en particular, al alumno en cuanto a sus } \\
\text { necesidades de aprendizaje geográfico. }\end{array}$ \\
\hline & & $\begin{array}{l}\text { Diseña, desarrolla y evalúa estrategias didácticas } \\
\text { para la solución de las necesidades de aprendizaje } \\
\text { geográfico del alumno. }\end{array}$ \\
\hline \multirow[t]{5}{*}{3} & \multirow[t]{5}{*}{$\begin{array}{l}\text { Dirige el proceso de enseñanza- } \\
\text { aprendizaje de la Geografía. }\end{array}$} & $\begin{array}{l}\text { Planifica el proceso de enseñanza-aprendizaje de } \\
\text { la Geografía, a partir de las necesidades de } \\
\text { aprendizaje geográfico de los alumnos. }\end{array}$ \\
\hline & & $\begin{array}{l}\text { Organiza el proceso de enseñanza-aprendizaje de } \\
\text { la Geografía articulando coherentemente sus } \\
\text { componentes humanos -profesor-grupo-alumno- } \\
\text { y culturales: objetivo-contenido-método-medio- } \\
\text { forma de organización-evaluación. }\end{array}$ \\
\hline & & $\begin{array}{l}\text { Determina y formula los objetivos de la clase de } \\
\text { Geografía a partir de su derivación gradual. }\end{array}$ \\
\hline & & $\begin{array}{l}\text { Conduce el proceso de formación y desarrollo de } \\
\text { conceptos y habilidades para el aprendizaje del } \\
\text { contenido geográfico. }\end{array}$ \\
\hline & & $\begin{array}{l}\text { Utiliza métodos, procedimientos y técnicas para la } \\
\text { enseñanza de los contenidos geográficos. }\end{array}$ \\
\hline
\end{tabular}




\begin{tabular}{|c|c|c|}
\hline & & $\begin{array}{l}\text { Selecciona, diseña y utiliza medios para la } \\
\text { enseñanza de los contenidos geográficos. }\end{array}$ \\
\hline & & $\begin{array}{l}\text { Modela situaciones de aprendizaje e instrumentos } \\
\text { de evaluación según nivel de asimilación del } \\
\text { contenido. }\end{array}$ \\
\hline & & $\begin{array}{l}\text { Desarrolla el proceso de enseñanza-aprendizaje de } \\
\text { la Geografía centrado en el aprendizaje del } \\
\text { alumno. }\end{array}$ \\
\hline & & $\begin{array}{l}\text { Evalúa el rendimiento del aprendizaje del alumno } \\
\text { de los contenidos geográficos. }\end{array}$ \\
\hline 4 & $\begin{array}{l}\text { Orienta la educación del grupo, } \\
\text { del alumno y de la familia; }\end{array}$ & $\begin{array}{l}\text { Identifica las necesidades de orientación educativa } \\
\text { del grupo, el alumno y la familia. }\end{array}$ \\
\hline & $\begin{array}{l}\text { haciendo énfasis en la } \\
\text { orientación vocacional hacia las }\end{array}$ & $\begin{array}{l}\text { Modela actividades de orientación educativa del } \\
\text { grupo, del alumno y de la familia. }\end{array}$ \\
\hline & $\begin{array}{l}\text { carreras geográficas y en la } \\
\text { gestión y la solución de } \\
\text { problemas medioambientales y } \\
\text { de ordenación territorial de su } \\
\text { espacio inmediato de residencia } \\
\text { y estudio. }\end{array}$ & $\begin{array}{l}\text { Dirige el proceso de orientación educativa, } \\
\text { haciendo énfasis en la orientación vocacional } \\
\text { hacia las carreras geográficas y en la gestión, y la } \\
\text { solución de problemas geográficos de su espacio } \\
\text { inmediato de residencia y estudio. }\end{array}$ \\
\hline 5 & $\begin{array}{l}\text { Coopera en el cumplimiento de } \\
\text { sus funciones profesionales }\end{array}$ & $\begin{array}{l}\text { Percibe lo que otros colegas de profesión y sus } \\
\text { alumnos pueden sentir (empatía pedagógica). }\end{array}$ \\
\hline & $\begin{array}{l}\text { pedagógicas en materia de } \\
\text { educación geográfica y } \\
\text { medioambiental. }\end{array}$ & $\begin{array}{l}\text { Interactúa positivamente con sus colegas de } \\
\text { profesión y con los alumnos en el proceso de } \\
\text { enseñanza-aprendizaje de la Geografía. }\end{array}$ \\
\hline & & $\begin{array}{l}\text { Trabaja en equipo con sus colegas de profesión y } \\
\text { con los alumnos en la solución de problemas de la } \\
\text { educación y, particularmente, del aprendizaje de } \\
\text { sus alumnos. }\end{array}$ \\
\hline 6 & $\begin{array}{l}\text { Investiga e innova en la } \\
\text { didáctica de la Geografía como }\end{array}$ & $\begin{array}{l}\text { Observa en su práctica pedagógica la } \\
\text { manifestación de una contradicción. }\end{array}$ \\
\hline & $\begin{array}{l}\text { vía para la superación y la } \\
\text { solución de los problemas }\end{array}$ & $\begin{array}{l}\text { Problematiza sobre una contradicción identificada } \\
\text { en su práctica pedagógica. }\end{array}$ \\
\hline & $\begin{array}{l}\text { educativos y, en particular, de } \\
\text { la educación geográfica. }\end{array}$ & $\begin{array}{l}\text { Examina en la teoría y en su experiencia la } \\
\text { evolución y el desarrollo del problema } \\
\text { identificado. }\end{array}$ \\
\hline & & $\begin{array}{l}\text { Mide la dimensión del problema identificado en } \\
\text { su práctica pedagógica. }\end{array}$ \\
\hline & & $\begin{array}{l}\text { Fundamenta la solución al problema identificado } \\
\text { desde sustentos teóricos, metodológicos y } \\
\text { prácticos de la investigación. }\end{array}$ \\
\hline
\end{tabular}




\begin{tabular}{|l|l|l|}
\hline & & $\begin{array}{l}\text { Comprueba la efectividad de una solución al } \\
\text { problema científico identificado. }\end{array}$ \\
\hline 7 & $\begin{array}{l}\text { Utiliza las tecnologías de la } \\
\text { información y la comunicación } \\
\text { en el cumplimiento de sus } \\
\text { funciones profesionales } \\
\text { pedagógicas y de gestión de la } \\
\text { información geográfica para } \\
\text { educar a las diferentes } \\
\text { generaciones. }\end{array}$ & $\begin{array}{l}\text { Busca la información geográfica mediante la } \\
\text { utilización de navegadores o motores de búsqueda } \\
\text { eficientes. }\end{array}$ \\
\cline { 3 - 3 } & $\begin{array}{l}\text { Procesa la información geográfica mediante la } \\
\text { utilización de procesadores de texto, hojas de } \\
\text { cálculo, presentaciones electrónicas, software, etc. }\end{array}$ \\
\cline { 3 - 3 } & $\begin{array}{l}\text { Comunica correctamente en su } \\
\text { actuación profesional } \\
\text { pedagógica como Profesor de } \\
\text { Geografía. }\end{array}$ & producto procesado de información geográfica. \\
\cline { 3 - 3 } & & Comprende lo leído o escuchado. \\
\cline { 3 - 3 } & Interactúa en función de emisor-receptor. \\
\cline { 3 - 3 } & Expresa oralmente sus razonamientos. \\
\cline { 3 - 4 } & Redacta correctamente sus razonamientos. \\
\hline
\end{tabular}

Tabla 1. Competencias profesionales pedagógicas en la formación docente en Geografía

Estas competencias emanan de la necesidad de formar un profesor de Geografía que domine el contenido de la ciencia que enseña. Tener dominio del contenido geográfico, en la actualidad, comienza por interpretar lo que ocurre en el espacio natural, para entonces entender la magnitud de los desequilibrios ocasionados en este y en el propio espacio social. En esta compresión es importante valorizar la ciencia que se enseña, no pocas veces reducida a disquisiciones epistémicas -geografía física versus geografía humana- o a clasificaciones divisorias -ciencia natural o ciencia social-. Tiene que comprenderse integralmente lo que se enseña y, al mismo tiempo demostrarse, con convicción, su utilidad para la vida y la posteridad.

Además, es necesario para un docente el estudio inacabable de la ciencia que enseña; pero también es importante y decisivo, desde su profesión pedagógica, estudiar la pedagogía y la didáctica para la dirección del aprendizaje, en el contexto escolar, de los contenidos, en este caso, geográficos que son transmitidos y que pasan por arreglos curriculares para ser asimilados por los alumnos. Esta particularidad queda definida en el objeto de la profesión, que en la carrera que se analiza "es el proceso pedagógico, por ser la expresión concreta de la labor educativa profesional que desarrolla el educador en la institución educativa". También queda definida en el objeto de trabajo, que "...es aquella parte de la realidad educativa escolar sobre la que recae la acción directa y sistemática del educador, que es, en el caso concreto de esta carrera, el proceso de enseñanzaaprendizaje de la Geografía". (MES, Cuba, 2016, p.8).

La formación y desarrollo de estas competencias profesionales pedagógicas son, probablemente una clave para el cumplimiento eficaz y eficiente de las funciones profesionales del profesor de Geografía que se expresan abreviadamente en: 
- La docencia geográfica y la aprehensión del sistema de trabajo metodológico para su perfeccionamiento continúo.

- La orientación educativa del grupo, el alumno y su familia; haciendo énfasis en la orientación vocacional hacia las carreras geográficas y en la gestión y solución de problemas medioambientales y de ordenamiento territorial de su espacio inmediato de residencia y estudio.

- La investigación e innovación didáctica como vía para la superación y solución de los problemas educativos y, en particular, de la educación geográfica.

La formación y el desarrollo de competencias profesionales no se limitan a la formación inicial. Esta perdura y se perfecciona a todo lo largo de la vida profesional.

\section{4.- Disciplina «Formación Laboral e Investigativa para la enseñanza de la Geografía»: su contribución a la formación, el desarrollo y la evaluación de competencias profesionales pedagógicas}

La disciplina «Formación Laboral e Investigativa para la enseñanza de la Geografía» funciona, en el actual plan de estudio - denominado E-, como disciplina principal integradora, es decir, como la disciplina que integra y completa los contenidos de las restantes disciplinas que conforman el plan del proceso docente-filosóficas, sociológicas, psicológicas, pedagógicas, didácticas, geográficas-. Esta tiene como finalidad evaluar integralmente la formación y el desarrollo de competencias profesionales pedagógicas del alumno de la «Licenciatura en Educación. Geografía», para el cumplimiento eficaz y eficiente de sus funciones profesionales pedagógicas.

La disciplina «Formación Laboral e Investigativa para la enseñanza de la Geografía», orientada hacia dicha finalidad, define como objeto de estudio, esencia de esta disciplina, el proceso de formación, desarrollo y evaluación de competencias, capacidades y habilidades profesionales pedagógicas en el alumno de la «Licenciatura en Educación. Geografía». Su contenido está integrado por los contenidos de la Práctica Laboral, de la Metodología de la Investigación Educativa y de la Didáctica de la Geografía.

La Práctica Laboral es asumida como un ejercicio pre-profesional, programado curricularmente que, en el ámbito de la formación profesional pedagógica, tiene la intención de entrenar al futuro docente en el cumplimiento de sus principales funciones profesionales pedagógicas; lo que se manifestará en su desempeño profesional competente. Su contenido es dinámico e integra los contenidos de los componentes académico, investigativo y extensionista.

La Metodología de la Investigación Educativa favorece la adquisición de la lógica de la investigación científico-educativa; así como de los métodos, procedimientos y técnicas. Asume el escenario de práctica laboral -la escuela- como fuente de la investigación educativa. Contribuye a la formación científica del alumno y a su 
participación efectiva en el perfeccionamiento continuo del Sistema Nacional de Educación y, en particular, de la educación geográfica de las diferentes generaciones, expresado en el proceso de enseñanza-aprendizaje de la Geografía.

La Didáctica de la Geografía constituye el "núcleo teórico fundamental" en el proceso de formación integral; dado que prepara para la dirección, es decir, la planificación, la organización, la ejecución y el control del proceso de enseñanzaaprendizaje de la Geografía; como esencia del objeto de trabajo de la profesión. El contenido de la Didáctica de la Geografía favorece el desarrollo teórico-práctico, en el dominio de una parte importante, de las competencias profesionales pedagógicas. Este se selecciona en estrecha relación con el contenido de las demás disciplinas de la carrera.

Estos contenidos trabajados en la formación de pregrado deben articularse coherentemente con las restantes disciplinas de dicha formación y fundar las bases de la formación para el empleo y de la formación posgraduada. Lograr eso significa desplegar una preparación docente-metodológica del personal docente encargado de la formación de docentes en Geografía. En esta preparación es necesario trasmitir los fundamentos teóricos y metodológicos de una formación basada en competencias profesionales; así como la función de cada una de las disciplinas que enseñan en esa dirección y en su relación con la disciplina principal integradora.

\section{4.- CONCLUSIONES}

Los resultados obtenidos a partir de la investigación documental realizada permitieron llegar a las conclusiones siguientes:

- A pesar de las disquisiciones teóricas existentes entre la definición constitutiva y operacional de la «competencia» y de los conceptos «habilidad», «hábito», «capacidad»y «aptitud», en la formación docente, en Cuba, se avanza teórica y metodológicamente en su desarrollo desde una concepción de formación continua basada en competencias.

- A pesar de la distinción entre los constructos psicológicos habilidad profesional, capacidad profesional y competencia profesional, estos se expresan en la actividad profesional del individuo y en los resultados que este obtiene. Además, se construyen e integran en las estructuras psíquicas y se proyectan en la actividad laboral del individuo; valorándose bajo criterios indicadores- preestablecidos como hábil, capaz, apto o competente para su función profesional.

- A pesar de la identificación y la definición de las competencias profesionales pedagógicas en la formación docente en Geografía; queda por resolver el problema de su instrumentación empírica y su evaluación en los diferentes 
momentos de la formación: formación de pregrado, formación para el empleo y formación posgraduada.

- La disciplina «Formación Laboral e Investigativa para la enseñanza de la Geografía» debe continuar perfeccionándose, desde el trabajo metodológico, en su contribución a la formación, el desarrollo y la evaluación de las competencias profesionales pedagógicas.

\section{BIBLIOGRAFÍA}

ACHIONG, G. \& DENIZ, D., (2012). Las competencias profesionales pedagógicas en la dirección de la formación inicial del profesional de la educación en la universidad. En Revista Congreso Universidad. Vol. I, $n^{\circ}$ 2, pp.1-10

ALVAREZ, P. (2016). Enseñar y aprender Geografía desde un enfoque cooperativotransformativo. En Revista de Didácticas Específicas, nº15, pp. 126-139.

ALVAREZ, P., et al. (2016). Programa de la disciplina formación laboral e investigativa para la enseñanza de la Geografía. En Ministerio de Educación Superior, Cuba (Comp.). Plan de Estudio E. Carrera Licenciatura en Educación. Geografía. La Habana: MES, Cuba.

ALVAREZ, P., PÉREZ, C. E. \& RECIO, P. P. (2015). La formación del profesor de Geografía en Cuba ante la pluralidad de enfoques epistemológicos de la ciencia geográfica: retos y perspectivas actuales. En revista científico-metodológica Varona, 61 .

BENEITONE, P. et al. (2007). Reflexiones y perspectivas de la educación superior en América Latina. Informe final Proyecto Tuning América Latina 2004-2007. Extraído el 11 de marzo de 2017, desde http://tuning.unideusto.org/tuningal

CARDOSO, L. (2008). Modelo del desempeño por competencias profesionales para el director de escuela primaria en San Miguel del Padrón. Tesis de doctorado. La Habana: Instituto Superior Pedagógico "Enrique José Varona" (inédito).

FERNÁNDEZ, A. M. (1996). La competencia comunicativa como factor de eficiencia profesional del educador. Tesis de doctorado. La Habana: Instituto Superior Pedagógico "Enrique José Varona” (inédito).

GARCÍA, M., et al. (2011). Tendencias de la formación del profesional en la educación superior, necesidad de la inserción de las competencias. En revista Pedagogía Universitaria Vol. XVI, No. 5, pp. 59-78

GONZÁLEZ, V. \& GONZÁLEZ, R. M. (2008). Competencias genéricas y formación profesional: un análisis desde la docencia universitaria. En Revista Iberoamericana de Educación, No. 47, pp. 185-209 
ILIASOV, I. I. \& YALIAODIS, V. (Comp., 1986). Antología de la psicología pedagógica y de las edades. La Habana: Editorial Pueblo y Educación.

MARTÍNEZ, M. (2007). La competencia tutoral de los docentes de la educación media en la formación de profesores generales integrales en el contexto de la universalización pedagógica. Tesis de doctorado. La Habana: Instituto Superior Pedagógico "Enrique José Varona” (inédito).

MES, Cuba (2016). Plan de Estudio E. Carrera Licenciatura en Educación. Geografía. La Habana: MES, Cuba.

NIETO, L. E. (2005). Modelo de superación profesional para el perfeccionamiento de las competencias profesionales en la actividad educativa con profesores de los institutos superiores pedagógicos. Tesis de doctorado. Villa Clara, Cuba: Instituto Superior Pedagógico "Félix Varela" (inédito).

NUSSBAUM, M. C. (2001). El cultivo de la humanidad: una defensa clásica de la reforma en la educación liberal [traducción de Juana Pailaya] $1^{\mathrm{a}}$ ed. Barcelona: Andrés Bello.

OECD (1997). Proyecto de Definición y Selección de Competencias (DeSeCo). Extraído el 22 de julio de 2015, desde www.OECD.org/edu/statistics/deseco www.deseco.admin.ch

PÁEZ, V. (2007). La formación de competencias en el profesional de la educación desde una perspectiva martiana y marxista. Tesis de doctorado. La Habana: Instituto Superior Pedagógico "Enrique José Varona” (inédito).

PARRA, I. B. (2002). Modelo didáctico para contribuir a la dirección del desarrollo de la competencia didáctica del profesional de la educación en formación inicial. Tesis de doctorado. La Habana: Instituto Superior Pedagógico "Enrique José Varona" (inédito).

PERRENOUD, Ph. (2004). Diez nuevas competencias docentes para enseñar. México: Quebecor World-Gráficas Monte Albán.

PETROVSKY, A. V. (s/f). Psicología pedagógica y de las edades. La Habana: Editorial Pueblo y Educación.

PINO, C. E. (2003). Un modelo para el aprendizaje de las habilidades profesionales como base para la formación de competencias profesionales, en el proceso de formación del licenciado en educación en la especialidad eléctrica, a través de la disciplina electrónica. Tesis de doctorado. Holguín, Cuba: Instituto Superior Pedagógico "José de la Luz y Caballero" (inédito).

SEN, A. K. (2000). Desarrollo y libertad. Barcelona: Editorial Planeta.

TEJEDA, R. \& SÁNCHEZ, P. R. (2008). La formación basada en competencias profesionales en los contextos universitarios. Holguín, Cuba: Centro de Estudios sobre Ciencias de la Educación Superior. Universidad de Holguín. "Oscar Lucero Moya”. 
DEFINICIÓN DE COMPENTENCIAS PROFESIONALES PEDAGÓGICAS EN LA FORMACIÓN DOCENTE EN GEOGRAFÍA

Pedro Álvarez Cruz

Revista de Didácticas Específicas, nº19, PP. 19-36

VENGUER, L. A. (1975). Pedagogía de las capacidades. En Ministerio de Educación, Cuba (Comp.). Superación para profesores de psicología (pp.169-178). La Habana: Editorial Pueblo y Educación.

WALKER, M., (2006). Higer Educations Pedagogies. Berkshire, UK: The society for research into Higer Education and Open University Press. 